\title{
Diagnosis and Management of Hepatitis C Infection in Primary Care Settings
}

\author{
Debra Guss, MS, APRN, ANP-C' , Jagannath Sherigar, MD', Paul Rosen, MD², and Smruti R. Mohanty, \\ $M D, M S F A C P^{1}$
}

'Division of Gastroenterology and Hepatobiliary Diseases, New York-Presbyterian Brooklyn Methodist Hospital, Brooklyn, USA; ${ }^{2}$ Department of Family Medicine, Brooklyn Hospital, Brooklyn, USA.

Hepatitis $\mathrm{C}$ virus (HCV) infection is a significant health problem worldwide, and is the leading cause of cirrhosis, hepatocellular carcinoma, and liver transplantation in the United States. The management of HCV has changed significantly over the last 5 years, as treatments have become simpler and more efficacious. Medication efficacy is now greater than $90 \%$, with a high barrier to resistance and few side effects. This review is a collaboration between primary care and hepatology providers to explore all aspects of $\mathrm{HCV}$ management: acute versus chronic $\mathrm{HCV}$ infection, transmission and testing, and diagnosis and treatment. Specific medications for the treatment of $\mathrm{HCV}$ infection are considered, and patient and medication factors including genotype, liver disease status, and comorbidities affecting medication choice are discussed. This is a new era for the management of $\mathrm{HCV}$ infection, and interested primary care physicians, family doctors, and general internists can be at the forefront of diagnosis, management, and treatment of HCV.

KEY WORDS: hepatitis C; primary care management; direct-acting antivirals (DAA).

$\mathrm{J}$ Gen Intern Med 33(4):551-7

DOI: $10.1007 / \mathrm{s} 11606-017-4280-y$

(c) Society of General Internal Medicine 2018

$\mathrm{H}$ epatitis $\mathrm{C}$ virus (HCV) infection is a significant worldwide health problem, representing an economic burden of over $\$ 6.5$ billion in the United States alone, ${ }^{1}$ and a leading cause of cirrhosis, hepatocellular carcinoma (HCC), and liver transplantation. While the prevalence of $\mathrm{HCV}$ infection peaked in 1994, the Centers for Disease Control and Prevention (CDC) estimates that there are currently 2.7-3.9 million persons in the United States with chronic HCV infection. ${ }^{2} \mathrm{~A}$ disturbing trend of increased infections was observed from 2006 to 2012 among those less than 30 years of age, mostly

Received September 8, 2017

Revised November 9, 2017

Accepted December 14, 2017

Published online January 19, 2018 due to increased injection drug use. ${ }^{3}$ A significant number of these patients with HCV are seen in the primary care setting, but have not been adequately tested, and therefore not diagnosed. A larger number of patients have been identified as having $\mathrm{HCV}$ and were referred to a gastroenterologist or hepatologist but lost to follow-up, had treatment deferred at the time of referral, or failed prior treatments and have not reengaged in care. With the development of simpler and more efficacious drug regimens, a greater opportunity exists to successfully manage chronically infected HCV patients at the primary care level and to cure patients of HCV infection. The door has opened for primary care physicians, family doctors, and general internists to diagnose, treat, and cure $\mathrm{HCV}$.

Treatment of HCV infection has changed dramatically since 1991 when the U.S. Food and Drug Administration (FDA) approved the first treatment for HCV infection. The standard of care at the time, interferon-alpha (subsequently pegylated interferon) and ribavirin, had poor cure rates of less than $50 \%$, with treatment requiring self-injection and risk of several severe adverse reactions ${ }^{4}$. The first oral medications, boceprevir and telaprevir (NS3/4a protease inhibitors), were approved in 2011 and were the first direct-acting antivirals (DAAs) to target HCV viral replication and clearance of infection. ${ }^{5}$ These NS3/4a protease inhibitors demonstrated $70-80 \%$ efficacy in curing HCV infections. ${ }^{6}{ }^{7}$ However, while the duration, efficacy, and side effects of these early oral medications were better than previous regimens, they still required the concomitant use of pegylated interferon injections and had significant side effects. Treatments continued to be improved and simplified, and in 2013, the first all-oral regimen sofosbuvir plus ribavirin was approved by the FDA. ${ }^{5}$ This combination of medications changed the face of $\mathrm{HCV}$ treatment, with easy dosing, few side effects, and high efficacy. More recently, DAAs with greater potency have been introduced, and HCV treatments continue to evolve. The new DAAs have efficacy rates greater than $90 \%$, a higher barrier to resistance, and fewer side effects. ${ }^{8}, 9$ A new era in $\mathrm{HCV}$ treatment has arrived, and for treatment-naïve patients without severe liver damage or significant comorbidities, treatment of $\mathrm{HCV}$ has been dramatically simplified, thus enabling 
primary care providers (PCPs) to diagnose, treat, and cure $\mathrm{HCV}$ without referral to specialists.

\section{ACUTE HCV INFECTION}

A complete understanding of the natural history of $\mathrm{HCV}$ infection is difficult, as acute HCV infection is not always recognized. Indeed, it is asymptomatic in most patients, though many present with vague flu-like symptoms. Acute hepatitis can occur 2-12 weeks after exposure (mean 7 weeks) and can last 2-12 weeks, with a range of symptoms, from complete absence of symptoms, to fatigue, myalgia, low-grade fever, dark urine, clay-colored stools, or jaundice. Elevation of serum alanine aminotransferase (ALT) levels more than 10 times the upper limit of normal (ULN) is unusual.

It is not always easy to determine whether a patient has an acute or chronic infection. Support for the diagnosis of acute infection includes a positive HCV RNA with negative antibody test (window period), or a positive $\mathrm{HCV}$ antibody test after prior negative antibody tests. ${ }^{10}$ For patients with no known exposure, HCV RNA should be monitored every 46 weeks for 6-12 months to determine spontaneous clearance versus persistence of $\mathrm{HCV}$ infection. ${ }^{11}$ The presence of acute infection warrants expedited linkage to care with a specialist engaged in the management of hepatitis patients, and patients should be counseled extensively in how to prevent transmission to others. Any sign of acute liver failure, such as hepatic encephalopathy or elevation in the international normalized ratio (INR) greater than 1.5 , should prompt referral to a liver transplant center. ${ }^{11}$

Spontaneous clearance of HCV infection occurs in some patients, generally within 6 months of infection, but it is unclear which patients will experience spontaneous clearance of acute HCV infection. A systemic review of 675 patients predicted a $25 \%$ rate of spontaneous viral clearance after infection, ${ }^{12}$ though other sources cite a rate of $20-50 \%$. $^{13}$ Thus, deferral of treatment for 6 months is recommended to see whether spontaneous clearance will occur. Treatment regimens for acute $\mathrm{HCV}$ infection are the same as for chronic infection. ${ }^{11}$

Treatment is indicated in patients who maintain HCV RNA for more than 6 months after initial infection. Those patients with spontaneous clearance, indicated by an undetectable HCV RNA, do not need HCV treatment. However, such patients should be counseled on the risk of reinfection, as $\mathrm{HCV}$ antibody positivity does not protect against future infection. ${ }^{11}$

\section{CHRONIC INFECTION}

Chronic HCV infection is characterized by a chronic inflammatory state, with liver injury that leads to the development of cirrhosis in $10-20 \%$ of patients over $20-30$ years of infection. ${ }^{14}$ The risk for progression to cirrhosis in patients with chronic $\mathrm{HCV}$ is multifactorial, including alcohol consumption and coinfection with hepatitis B virus (HBV) or HIV. Once a patient has cirrhosis, there is a $1-5 \%$ annual risk of $\mathrm{HCC}$, and a $5 \%$ risk per year of decompensation, including ascites, variceal hemorrhage, or hepatic encephalopathy. ${ }^{15}$

\section{TRANSMISSION AND TESTING}

Transmission of HCV occurs primarily through percutaneous means, including blood transfusions (before screening of the blood supply in 1992), intravenous drug use with needle sharing, needle-stick injuries, mother-to-child exposure to infected blood, or less frequently through unprotected sex with blood-to-blood contact. ${ }^{2}$

Testing for HCV infection is based on previous or current exposure to risk factors, along with cohort testing. The CDC recommends one-time HCV testing for persons in the 19451965 birth cohort, without prior ascertainment of risk. This population has a sixfold higher prevalence of $\mathrm{HCV}$ than adults of other age groups, representing $81 \%$ of patients with chronic $\mathrm{HCV} .{ }^{16}$ Other persons should be screened for HCV infection based on the presence of risk factors for HCV exposure. Patients with prior or current injection or intranasal drug use should be tested. If exposure was in the past, one-time testing should be performed. Persons who continue to inject drugs should receive annual blood testing for $\mathrm{HCV}$ infection. Others considered to have prior risk exposure are patients who have been on long-term hemodialysis; those who had a blood transfusion prior to 1992, when testing of the blood supply for HCV began; health care, emergency medical, and public safety workers; children born to HCV-infected women; persons who were ever incarcerated; and patients with a history of parenteral injections. ${ }^{11}$

There is also evidence that these screening recommendations should be broadened to include more of the general population, as $\mathrm{HCV}$ is now believed to be more ubiquitous than originally thought. Studies have reported that universal testing for HCV would be cost-efficient and would reduce liver-related morbidity and mortality. ${ }^{17} \mathrm{Al}-$ though guidelines do not yet reflect this thinking, there is likely to be further discussion of this broadening of screening guidelines.

\section{ACCURATE DIAGNOSIS OF HCV}

Diagnostic evaluation for HCV begins with a serum antibody test. A non-reactive result means that there has been no exposure to $\mathrm{HCV}$, but a reactive antibody cannot distinguish between current and past infection. Approximately $15-25 \%$ of persons who are exposed to HCV spontaneously clear the virus from their bodies without treatment and do not develop chronic infection ${ }^{2}$; these patients will have a positive HCV antibody test although they do not have an active infection. Patients who were previously treated and cured will also show 
a positive antibody test. In those patients with a reactive or indeterminate/equivocal antibody test, a qualitative or quantitative HCV RNA test should be ordered, which is specific for active infection. If $\mathrm{HCV}$ RNA is detected, diagnosis of $\mathrm{HCV}$ infection is confirmed. Failure to detect HCV RNA indicates a past HCV infection that was subsequently cleared or a falsepositive result. Patients with a reactive antibody test and an HCV RNA viral load number greater than the level of detection have an active $\mathrm{HCV}$ infection and are eligible for treatment $^{11}$ (Fig. 1).

\section{TREATMENT CONSIDERATIONS}

$\mathrm{HCV}$ genotype, prior HCV treatment experience, comorbidities, and degree of liver fibrosis will influence treatment decisions and follow-up care. The goal of treatment for $\mathrm{HCV}$ is clearance of infection, thus reducing the progression of liver disease to cirrhosis and its related complications such as end-stage liver disease and HCC, and a reduction in liver-related morbidity and mortality and allcause mortality. Treatment is recommended for all patients with HCV except those with short life expectancy (less than 12 months). ${ }^{11}$

\section{Genotype and HCV Treatment Regimens}

There are six common genotypes of $\mathrm{HCV}$, which vary in geographical distribution, progression of liver disease, and treatment response to medications. Approximately $75 \%$ of persons in the United States with HCV have genotype 1 (subtypes $1 \mathrm{a}$ or $1 \mathrm{~b}$ ), and $20-25 \%$ have genotype 2 or 3 , with small numbers of patients infected with genotypes 4, 5, or 6 . Genotype 3 is more frequently associated with intravenous drug use and with increased rates of steatosis, faster progression of the disease to cirrhosis, and increased rates of HCC. It is also associated with lower rates of response to DAAs, though this difference may be overcome with most newer regimens. ${ }^{18,19}$

Patients with all genotypes can be treated for 8 16 weeks with a daily, all-oral medication regimen of 13 pills. Treatment duration is determined by many factors, including $\mathrm{HCV}$ genotype, prior treatment with $\mathrm{HCV}$ medications, and the presence of cirrhosis. There are currently ten FDA-approved DAA treatment regimens. Medication regimens comprise DAAs used in combination to inhibit different steps in the $\mathrm{HCV}$ life cycle at the NS3/4A, NS5A, and NS5B receptors. Genotype has historically played a major role in determining appropriate medication regimens for individual patients. Currently, however, three

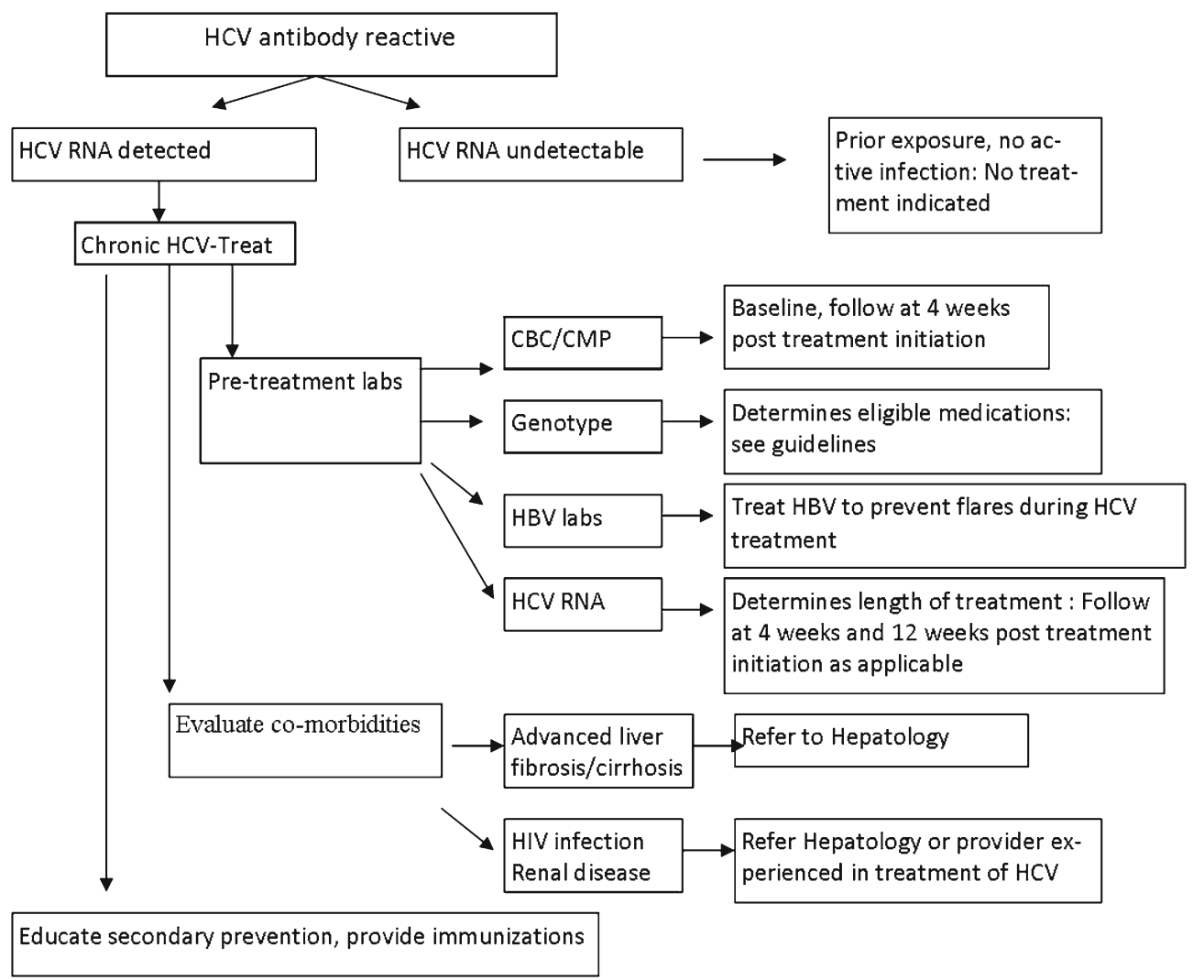

Figure 1: Workup of patient with $\mathrm{HCV}$ antibody reactive. Key: $\mathrm{HCV}$ : Hepatitis C; HBV: Hepatitis $\mathrm{B}$

Figure 1 Workup of patient with $\mathrm{HCV}$ antibody reactive result. HCV, hepatitis C; HBV, hepatitis B. 
regimens can be used across all genotypes, including two drug regimens just approved in July and August 2017 (Table 1). The main adverse effects of DAA medications are fatigue, GI side effects, and headache, with some variation among regimens. See Table 1 for a complete, updated list of FDA-approved medications and dosing considerations for treatment-naïve patients with and without cirrhosis. ${ }^{20-27}$

The newest DAA, glecaprevir and pibrentasvir, is the first 8 -week treatment approved by the FDA for all genotypes in the treatment-naïve patients without cirrhosis. ${ }^{26,27}$ Alternatively, ledipasvir/sofosbuvir can be used for 8 weeks in patients with genotype 1 with low levels of viremia (less than 6 million copies) and no cirrhosis. ${ }^{21}$ Most other FDA treatment regimens are used for 12 weeks in treatment-naïve patients without cirrhosis (Table 1). Treatment-naïve patients with genotype $1 \mathrm{a}$ and NS5a mutations will require 16 weeks of treatment with elbasvir/grazoprevir, though this mutation is rare. ${ }^{11}$ Therefore, NS5a testing should be performed at baseline in genotype 1a patient if the provider intends to treat with elbasvir/grazoprevir therapy.

Treatment-experienced patients and patients with cirrhosis will require 12-24 weeks of treatment. Two new DAAs have specific indications for treatment-experienced patients who have failed prior DAA regimens. Sofosbuvir/velpatasvir/ voxilaprevir was approved in July 2017, and is indicated for 12 weeks in all genotypes for patients who have been previously treated. ${ }^{28}$ Glecaprevir/pibrentasvir has been approved for patients with genotype 1 who were treated with either an NS5A inhibitor or an NS3/4A protease inhibitor (but not both) for 12 weeks, patients with genotype 1,2,4,5, or 6 previously treated with other non-NS5A or NS3/4A medications for 8 weeks, and genotype 3 treatment-experienced patients for 16 weeks.

\section{Liver Disease Status}

Evaluation of the degree of liver fibrosis is essential in this patient population. Many patients with cirrhosis are not diagnosed until they are late in the disease process, which leads to worse outcomes, including complications of portal hypertension (ascites, variceal hemorrhage, hepatic encephalopathy, and HCC). ${ }^{29}$ Baseline blood work and ultrasound of the abdomen should be performed, along with non-invasive tests for liver fibrosis. Biomarkers for evaluating liver fibrosis such as FibroSure or FibroTest are readily available and can be used to estimate the extent of liver fibrosis. Other non-invasive tests for fibrosis, including transient elastography (commonly

Table 1 Hepatitis C Medications

\begin{tabular}{|c|c|c|c|c|}
\hline Generic & Brand & Genotype(s) & Drug class & Considerations \\
\hline Sofosbuvir/velpatasvir & Epclusa & $1-6$ & $\begin{array}{l}\text { Sofosbuvir: NS5B polymerase } \\
\text { inhibitor } \\
\text { Velpatasvir: NS5A inhibitor }\end{array}$ & Cannot be used in renal disease \\
\hline Elbasvir/grazoprevir & Zepatier & 1,4 & $\begin{array}{l}\text { Elbasvir: NS5A inhibitor } \\
\text { Grazoprevir: NS3/4A protease } \\
\text { inhibitor }\end{array}$ & $\begin{array}{l}\text { Can be used with renal disease } \\
\text { Not to be used in decompensated (Child B/C) } \\
\text { cirrhosis }\end{array}$ \\
\hline Daclatasvir & Daklinza & 1,3 & $\begin{array}{l}\text { Daclatasvir: NS5A inhibitor } \\
\text { Used with sofosbuvir: NS5B } \\
\text { polymerase inhibitor }\end{array}$ & $\begin{array}{l}\text { Efficacy reduced in cirrhosis } \\
\text { Different dosage pills available for concomitant use } \\
\text { of some drugs, including HIV medications }\end{array}$ \\
\hline Glecaprevir/pibrentasvir & Mavyret & $1-6$ & $\begin{array}{l}\text { Glecaprevir: NS3/4A prote- } \\
\text { ase inhibitor } \\
\text { Pibrentasvir: NS5A inhibitor }\end{array}$ & $\begin{array}{l}\text { Not recommended in patients with Child B, } \\
\text { contraindicated in Child C } \\
\text { Can be used in renal patients } \\
\text { DAA treatment failures with NS5A or NS3/4A } \\
\text { failures }\end{array}$ \\
\hline $\begin{array}{l}\text { Ombitasvir, paritaprevir, } \\
\text { ritonavir }\end{array}$ & Technivie & 4 & $\begin{array}{l}\text { Ombitasvir: NS5A inhibitor } \\
\text { Paritaprevir: NS3/4A protease } \\
\text { inhibitor } \\
\text { Ritonavir: CYP3A inhibitor }\end{array}$ & $\begin{array}{l}\text { Contraindicated in patients with decompensated } \\
(\text { Child B/C) cirrhosis } \\
\text { With ribavirin }\end{array}$ \\
\hline $\begin{array}{l}\text { Ombitasvir, paritaprevir, } \\
\text { ritonavir, dasabuvir }\end{array}$ & $\begin{array}{l}\text { Viekira Pak } \\
\text { (XR) }\end{array}$ & 1 & $\begin{array}{l}\text { Ombitasvir: NS5A inhibitor } \\
\text { Paritaprevir: NS3/4A protease } \\
\text { inhibitor } \\
\text { Ritonavir: CYP3A inhibitor } \\
\text { Dasabuvir: NS5B polymerase } \\
\text { inhibitor }\end{array}$ & $\begin{array}{l}\text { Contraindicated in patients with decompensated } \\
\text { (Child B/C) cirrhosis } \\
\text { With ribavirin in 1a patients }\end{array}$ \\
\hline Ledipasvir/sofosbuvir & Harvoni & $1,4,5,6$ & $\begin{array}{l}\text { Sofosbuvir: NS5B polymerase } \\
\text { inhibitor } \\
\text { Ledipasvir: NS5A inhibitor }\end{array}$ & Cannot be used in renal disease \\
\hline Simeprevir & Olysio & 1 & $\begin{array}{l}\text { Simeprevir: NS3/4A protease } \\
\text { inhibitor }\end{array}$ & $\begin{array}{l}\text { Used in combination with sofosbuvir } \\
\text { Contraindicated in patients with decompensated } \\
\text { (Child B/C) cirrhosis }\end{array}$ \\
\hline Sofosbuvir & Sovaldi & $1-6$ & $\begin{array}{l}\text { Sofosbuvir: NS5B polymerase } \\
\text { inhibitor }\end{array}$ & Used in combination with other medications \\
\hline $\begin{array}{l}\text { Sofosbuvir/velpatasvir/ } \\
\text { voxilaprevir }\end{array}$ & Vosevi & $\begin{array}{l}1-6 \\
\text { Prior } \\
\text { treatment } \\
\text { experience }\end{array}$ & $\begin{array}{l}\text { Sofosbuvir: NS5B polymerase } \\
\text { inhibitor } \\
\text { Velpatasvir: NS5A inhibitor } \\
\text { Voxilaprevir: NS3/4A prote- } \\
\text { ase inhibitor }\end{array}$ & $\begin{array}{l}\text { Genotypes } 1-6 \text { previously treated with NS5A } \\
\text { Genotypes } 1,3 \text { previously treated with sofosbuvir } \\
\text { without NS5A }\end{array}$ \\
\hline
\end{tabular}


known as FibroScan), acoustic radiation force impulse (ARFI) imaging, and magnetic resonance elastography (MRE), can also be used with good diagnostic accuracy. ${ }^{30}$ These methods should be combined for use in conjunction with other clinical findings to increase the validity of results. ${ }^{31}$ Any patient with advanced liver fibrosis or cirrhosis should be referred to a specialist with expertise in liver disease management. Liver biopsy is no longer indicated as a routine test unless there is a concern for other concomitant liver diseases or clinical ambiguity regarding cirrhosis of the liver despite other noninvasive tests.

In patients who are determined to have stage 3 liver fibrosis (pre-cirrhotic state) or cirrhosis, ultrasound of the abdomen is recommended every 6 months to screen for HCC, even postHCV treatment. ${ }^{32-34}$ However, it is known that these recommendations are not routinely followed, and every-6-month ultrasound surveillance rates are as low as $1.7-17.4 \% .^{35} \mathrm{~Pa}$ tients diagnosed with cirrhosis should also be referred to a gastroenterologist to screen for esophageal varices, as at least two-thirds of patients with cirrhosis will develop varices in their lifetime. Bleeding from varices develops in 30-40\% of these patients, with a high rate of mortality associated with first esophageal variceal hemorrhage $(20-35 \%){ }^{36}$

The treatment of $\mathrm{HCV}$ differs among patients with liver cirrhosis. The NS3/4A protease inhibitors are contraindicated in patients with decompensated cirrhosis (Child B or C). Patients with cirrhosis require a longer course of treatment, and the addition of ribavirin in some regimens. It is recommended that these patients be referred to a specialist for treatment and management of cirrhosis.

Comorbidities. Comorbidities such as renal impairment, advanced liver disease including cirrhosis, HIV disease, and pregnancy $^{37}$ add a level of treatment complexity, and collaboration with a hepatologist or infectious disease specialist is recommended unless the health care provider has extensive experience and comfort in treating such patients.

Coinfection with HIV and HCV is common, as the two viruses share a common route of infection. Coinfection is found in 10-30\% of all patients with HIV, and up to $90 \%$ of patients with HIV who inject drugs. ${ }^{38}$ HIV is also known to accelerate liver fibrosis, so appropriate treatment of patients with HIV coinfection is critical. ${ }^{11}$ The major issue in the treatment of such patients, however, is the risk of drug-drug interactions. $^{39}$ Adjustments in HIV medications are often needed, so close collaboration with infectious disease providers is recommended.

Treatment of patients with $\mathrm{HCV}$ and renal disease also requires specialized care. The prevalence of $\mathrm{HCV}$ in patients on hemodialysis is high, ranging from 7.8 to $44 \%,{ }^{40}$ and concomitant $\mathrm{HCV}$ and renal disease is associated with worse outcomes than either disease process alone. ${ }^{41}$ Three medications are currently FDA-approved for the treatment of patients with $\mathrm{HCV}$ infection and renal disease. Glecaprevir and pibrentasvir attained a sustained viral response (SVR) of 98\% across genotypes 1-6, including patients with severe chronic kidney disease (CKD) and on hemodialysis, regardless of previous treatment status or presence of compensated cirrhosis. Glecaprevir/pibrentasvir is the first medication approved for genotypes 2, 3, 5, and 6 in patients with renal disease. $^{42}$ For patients with genotypes 1 and 4, two older DAAs are also approved for the treatment of $\mathrm{HCV}$ in those with a glomerular filtration rate (GFR) of $<30 \mathrm{~mL} / \mathrm{min}$. The C-SURFER trial demonstrated a 94\% SVR rate with grazoprevir and elbasvir, with few side effects. ${ }^{40}$ The RUBY-1 trial reported an SVR rate of $90 \%$ in 20 patients treated with the combination of ombitasvir, paritaprevir, ritonavir, and dasabuvir, with the addition of ribavirin in patients with genotype $1 \mathrm{a} .^{43}$

Treatment is indicated for elderly patients with HCV except in the case of short life expectancy. No significant increase in the side effects of HCV medications is seen in the elderly, and no dose adjustment is needed, ${ }^{44}$ though there is an increased number of drug-drug interactions. ${ }^{45}$ Women of childbearing age should be evaluated for pregnancy, as HCV medications have not been assessed for safety in pregnant women, and ribavirin is teratogenic (category X). New DAAs are pregnancy category $\mathrm{B}$ or $\mathrm{C}$, but there are no medications for treatment of $\mathrm{HCV}$ that are currently recommended in pregnancy, and so women undergoing HCV treatment should avoid pregnancy. ${ }^{11}$

Prior Exposure to Hepatitis B. All DAAs for the treatment of $\mathrm{HCV}$ now have a black box warning to check the HBV infection status in patients who are to be treated for $\mathrm{HCV}$. This is due to the risk of reactivation of HBV when patients with HCV infection are undergoing or have just completed treatment. This reactivation of $\mathrm{HBV}$ has led to liver failure or death in a small number of patients during treatment. ${ }^{46,47}$ Patients who are not immune to hepatitis A and B should be immunized and should receive other maintenance immunizations as well, including yearly influenza vaccine, and pneumonia, tetanus, and zoster as applicable. Hepatitis $A$ and $B$ vaccinations can be given as a combined vaccine (Twinrix) at 0,1 , and 6 months or in single antigen injections. Any person with risk factors for hepatitis A or B, or anyone with chronic liver disease including $\mathrm{HCV}$, cirrhosis, fatty liver, or other liver disease, should be given hepatitis A and B immunizations. $^{48}$

Other Considerations. Evaluation of other medical history, medication and herbal use, and illicit drug and alcohol use should be completed per the standard of care. Interactions with antiarrhythmics can occur, particularly amiodarone, which is linked to severe cardiac issues and death when taken with sofosbuvir-containing regimens. ${ }^{49}$ Other medications including anticonvulsants, HIV drugs, statins, and proton pump inhibitors (which may require dose adjustments) should be explored. There are no contraindications to the use of statins 
with DAAs, though some medications require administration of lower-dose statins.

Some insurance carriers require documented evidence of abstinence from illicit drug use in order to approve medications, though treatment of patients with recent or active drug use is no longer seen as an absolute contraindication to treatment. However, it is recommended that patients who are active drug users be treated in a multidisciplinary care setting to reduce the risk of $\mathrm{HCV}$ reinfection. ${ }^{11}$

\section{SUSTAINED VIROLOGIC RESPONSE}

Quantitative HCV (HCV RNA) viral load testing is recommended 4 weeks into therapy and at 12, 24, and 48 weeks following completion of therapy. ${ }^{11}$ SVR, also known as a virologic cure, is defined as an undetectable viral load at 12 weeks after the completion of therapy. SVR has traditionally been tested at 24 weeks after completion of treatment, and is commonly known as $\mathrm{SVR}_{24}$. However, a 2015 study by Yoshida et al. showed that among 779 patients who achieved SVR at 12 weeks, 777 achieved SVR $_{24}$, demonstrating $99.7 \%$ concordance between these two results. ${ }^{50}$ Predictably, many providers now check both $\mathrm{SVR}_{12}$ and $\mathrm{SVR}_{24}$ to assess for virologic cure. Recent recommendations are to confirm longterm SVR at 48 weeks, given a late relapse rate of $\pm 0.5 \%{ }^{51}$ No further confirmation of SVR post- 48 weeks is indicated.

\section{ROLE OF THE PRIMARY CARE PROVIDER (PCP) IN TREATING HCV}

In general, it is our belief that PCPs interested in the treatment of HCV can provide safe and effective treatment. This ability was demonstrated by PCPs and nurse practitioners (NPs) in the ASCEND study, where the outcomes for PCPs and NPs trained in the care of $\mathrm{HCV}$-infected patients were similar to those for specialists in HCV treatment. ${ }^{52}$ The use of specialty pharmacies can assist providers with medication authorizations and approval - the most difficult part of the treatment of HCV. Evaluation of patients for HCV treatment also provides PCPs an opportunity for contact with patients that may also have cirrhosis, enabling the evaluation and referral of these patients to specialist expertise in liver disease, including liver transplant evaluation. Furthermore, any PCPs who are comfortable managing complex $\mathrm{HCV}$ patients such as those with cirrhosis, HIV coinfection, $\mathrm{HCV}$ with $\mathrm{CKD}$ /end-stage renal disease (ESRD), or HCV with $\mathrm{HCC}$ should be able to treat chronic HCV in these patients. The HCV Guidance web aid (https://www.hcvguidelines.org/) is an important tool for guiding the management and treatment of hepatitis $\mathrm{C}$ patients, as it is a living document which will continue to provide updated information for clinicians. The time has arrived for PCPs to diagnose, treat, and cure patients with $\mathrm{HCV}$, and interested PCPs should be able to add HCV as a disease that they can successfully manage in a primary care setting.

Acknowledgements:

Funding: There were no sources of funding for this manuscript.

Corresponding Author: Debra Guss, MS, APRN, ANP-C; Division of Gastroenterology and Hepatobiliary Diseases New York-Presbyterian Brooklyn Methodist Hospital, Brooklyn, USA (e-mail: Dag9132@nyp. org).

\section{Compliance with Ethical Standards:}

Conflict of Interest: Dr. Smruti Mohanty is a speaker and advisor for Gilead, AbbVie, and Merck. All other authors declare that they have no conflict of interest.

\section{REFERENCES}

1. Razavi H, ElKhoury AC, Elbasha E, Estes C, Pasini K, Poynard T, et al. Chronic hepatitis $\mathrm{C}$ virus (HCV) disease burden and cost in the United States. Hepatology. 2013;57(6):2164-70.

2. Centers for Disease Control \& Prevention. Hepatitis C FAQs for Health Professionals 2008. Available from: https://www.cdc.gov/hepatitis/hcv/ hcvfaq.htm Retrieved September 15, 2017.

3. Zibbell JE, Iqbal $\mathbf{K}$, Patel $\mathbf{R}$, Suryaprasad A, Sanders $\mathbf{K}$, MooreMoravian L, et al. Increases in hepatitis $\mathrm{C}$ virus infection related to injection drug use among persons aged $\leq 30$ years-Kentucky, Tennessee, Virginia, and West Virginia, 2006-2012. MMWR Morb Mortal Wkly Rep. 2015;64(17):453-8

4. Williford SE, McGivern DR. Mechanism of Action of Direct-Acting Antivirals: New Insights into the HCV Life Cycle. In: Miyamura T, Lemon S, Walker C, Wakita T, eds. Hepatitis C Virus II. Tokyo: Springer; 2016:287-301.

5. US Food and Drug Administration. Hepatitis B and C Treatments. 2017. Available from: https://www.fda.gov/ForPatients/Illness/HepatitisBC/ ucm408658.htm. Retrieved July 14, 2017.

6. Kwo PY, Lawitz EJ, McCone J, Schiff ER, Vierling JM, Pound D, et al. Efficacy of boceprevir, an NS3 protease inhibitor, in combination with peginterferon alfa- $2 \mathrm{~b}$ and ribavirin in treatment-naive patients with genotype 1 hepatitis C infection (SPRINT-1): an open-label, randomised, multicentre phase 2 trial. Lancet. 2010;376(9742):705-16.

7. Hayashi N, Okanoue T, Tsubouchi H, Toyota J, Chayama K, Kumada H. Efficacy and safety of telaprevir, a new protease inhibitor, for difficultto-treat patients with genotype 1 chronic hepatitis C. J Viral Hepat. 2012;19(2).

8. Reddy KR, Bourlière M, Sulkowski M, Omata M, Zeuzem S, Feld JJ, et al. Ledipasvir and sofosbuvir in patients with genotype 1 hepatitis $\mathrm{C}$ virus infection and compensated cirrhosis: An integrated safety and efficacy analysis. Hepatology. 2015;62(1):79-86.

9. Lawitz E, Makara M, Akarca US, Thuluvath PJ, Preotescu LL, Varunok P, et al. Efficacy and safety of ombitasvir, paritaprevir, and ritonavir in an open-label study of patients with genotype lb chronic hepatitis $\mathrm{C}$ virus infection with and without cirrhosis. Gastroenterology. 2015;149(4):971-80. e1.

10. Cox AL, Netski DM, Mosbruger T, Sherman SG, Strathdee S, Ompad D, et al. Prospective evaluation of community-acquired acute-phase hepatitis C virus infection. Clin Infect Dis. 2005;40(7):951-8.

11. Aasld-Idsa H. Guidance panel. Hepatitis C guidance: AASLD-IDSA recommendations for testing, managing, and treating adults infected with hepatitis C virus. Hepatology. 2015;62(3):932-54.

12. Micallef J, Kaldor J, Dore G. Spontaneous viral clearance following acute hepatitis $\mathrm{C}$ infection: a systematic review of longitudinal studies. J Viral Hepat. 2006;13(1):34-41.

13. Kamal SM. Acute hepatitis C: a systematic review. Am J Gastroenterol. 2008; 103(5): 1283-97.

14. D'Amico G, Garcia-Tsao G, Pagliaro L. Natural history and prognostic indicators of survival in cirrhosis: A systematic review of 118 studies. J Hepatol. 44(1):217-31.

15. Westbrook RH, Dusheiko G. Natural history of hepatitis C. J Hepatol. 2014;61(1):S58-S68.

16. Reilley B. Birth Cohort Testing for Hepatitis C Virus-Indian Health Service 2012-2015. MMWR Morb Mortal Wkly Rep. 2016;65(18):467-9. 
17. Coffin PO, Scott JD, Golden MR, Sullivan SD. Cost-effectiveness and population outcomes of general population screening for hepatitis C. Clin Infect Dis. 2012;54(9):1259-71.

18. Chan A, Patel K, Naggie S. Genotype 3 Infection: The Last Stand of Hepatitis C Virus. Drugs. 2017;77(2):131-44.

19. Isaura Cunha M, Maria Lucia Gomes F, Renata Mello P, Christine Takemi E, Silvia Naomi de Oliveira U, Roberto José de C-F, et al. Do differences exist between chronic hepatitis $\mathrm{C}$ genotypes 2 and 3 ? Rev Soc Bras Med Trop. 2014;(2):143.

20. Zeuzem S, Ghalib R, Reddy KR, Pockros PJ, Ari ZB, Zhao Y, et al. Grazoprevir-Elbasvir Combination Therapy for Treatment-Naive Cirrhotic and Noncirrhotic Patients With Chronic Hepatitis C Virus Genotype 1, 4, or 6 Infection: A Randomized Trial. Ann Intern Med. 2015;163(1):1-13.

21. Kowdley KV, Gordon SC, Reddy KR, Rossaro L, Bernstein DE, Lawitz E, et al. Ledipasvir and sofosbuvir for 8 or 12 weeks for chronic HCV without cirrhosis. N Engl J Med. 2014;370(20):1879-88.

22. Feld JJ, Jacobson IM, Hézode C, Asselah T, Ruane PJ, Gruener N, et al. Sofosbuvir and velpatasvir for HCV genotype 1, 2, 4, 5, and 6 infection. N Engl J Med. 2015;373(27):2599-607.

23. Lawitz E, Sulkowski MS, Ghalib R, Rodriguez-Torres M, Younossi ZM, Corregidor A, et al. Simeprevir plus sofosbuvir, with or without ribavirin to treat chronic infection with hepatitis $\mathrm{C}$ virus genotype 1 in nonresponders to pegylated interferon and ribavirin and treatment-naive patients: the COSMOS randomised study. Lancet. 2014;384(9956): 175665.

24. Feld JJ, Kowdley KV, Coakley E, Sigal S, Nelson DR, Crawford D, et al. Treatment of $\mathrm{HCV}$ with ABT-450/r-ombitasvir and dasabuvir with ribavirin. N Engl J Med. 2014;370(17):1594-603.

25. Nelson DR, Cooper JN, Lalezari JP, Lawitz E, Pockros PJ, Gitlin N, et al. All-oral 12-week treatment with daclatasvir plus sofosbuvir in patients with hepatitis $\mathrm{C}$ virus genotype 3 infection: ALLY-3 phase III study. Hepatology. 2015;61(4):1127-35.

26. Hassanein TI, Wyles DL, Wang S, Kwo PY, Shiffman ML, Younes Z, et al., eds. Glecaprevir/Pibrentasvir Demonstrates High SVR Rates in Patients with HCV Genotype 2, 4, 5, or 6 Infection without Cirrhosis Following an 8-Week Treatment Duration (SURVEYOR-II, Part 4). In vitro. 2016;2:3

27. Wyles DL, Poordad F, Wang S, Alric L, Felizarta F, Kwo PY, et al. SURVEYOR-II, part 3: efficacy and safety of glecaprevir/pibrentasvir (ABT-493/ABT-530) in patients with hepatitis C virus genotype 3 infection with prior treatment experience and/or cirrhosis. In Vitro. 2016; $1: 2$.

28. Bourliere M, Gordon SC, Ramji A, Ravendhran N, Tran TT, Hyland RH, et al. Sofosbuvir/Velpatasvir/Voxilaprevir for 12 weeks as a Salvage regimen in NS5A inhibitor-experienced patients with genotype 1-6 infection: the phase 3 POLARIS-1 study. Hepatology. 2016;64:1-136.

29. Volk ML, Tocco RS, Bazick J, Rakoski MO, Lok AS. Hospital readmissions among patients with decompensated cirrhosis. Am J Gastroenterol. 2012;107(2):247-52.

30. Papastergiou V, Tsochatzis E, Burroughs AK. Non-invasive assessment of liver fibrosis. Ann Gastroenterol. 2012;25(3):218.

31. Boursier J, De Ledinghen V, Zarski JP, Fouchard-Hubert I, Gallois Y, Oberti F, et al. Comparison of eight diagnostic algorithms for liver fibrosis in hepatitis C: new algorithms are more precise and entirely noninvasive. Hepatology. 2012;55(1):58-67.

32. European Association For The Study Of The Liver. EASL-EORTC clinical practice guidelines: management of hepatocellular carcinoma. J Hepatol. 2012;56(4):908-43.

33. Bruix J, Sherman M. Management of hepatocellular carcinoma: an update. Hepatology. 2011;53(3):1020-2.

34. Omata M, Lesmana LA, Tateishi R, Chen P-J, Lin S-M, Yoshida H, et al. Asian Pacific Association for the Study of the Liver consensus recommendations on hepatocellular carcinoma. Hepatol Int. 2010;4(2):439-74.

35. Guss DA, Mohanty SR. Integrative review: patient and provider factors related to hepatocellular carcinoma surveillance in patients with liver cirrhosis. Transl Lung Cancer Res. 2017;6(2):450-6.

36. Jensen DM. Endoscopic screening for varices in cirrhosis: findings, implications, and outcomes. Gastroenterology. 2002;122(6):1620-30.

37. Gayam V, Mukhtar O, Khalid M, Garlapati P, Sherigar J, Khan A, et al Direct Acting Antivirals in HIV-HCV Co-infection: A Community Based Retrospective Cohort Study. Am J Gastroenterol. 2016;111:S377-S.

38. Wyles DL, Sulkowski MS, Dieterich D. Management of hepatitis C/HIV coinfection in the era of highly effective hepatitis $\mathrm{C}$ virus direct-acting antiviral therapy. Clin Infect Dis. 2016;63(suppl_1):S3-S11.

39. MacBrayne CE, Kiser JJ. Pharmacologic considerations in the treatment of hepatitis $\mathrm{C}$ virus in persons with HIV. Clin Infect Dis. 2016;63(suppl_1):S12-S23.

40. Lens S, Rodriguez-Tajes S, Llovet L-P, Maduell F, Londoño M-C Treating Hepatitis C in Patients with Renal Failure. Dig Dis. 2017;35(4):339-46.

41. Fabrizi F, Martin P, Messa P. New treatment for hepatitis C in chronic kidney disease, dialysis, and transplant. Kidney Int. 2016;89(5):988-94.

42. Forns X, Lee S, Valdes J, Lens S, Ghalib R, Aguilar H, et al. GS-006EXPEDITION-I: efficacy and safety of glecaprevir/pibrentasvir in adults with chronic hepatitis $\mathrm{C}$ virus genotype $1,2,4,5$ or 6 infection and compensated cirrhosis. J Hepatol. 2017;66(1):S3-S4.

43. Pockros PJ, Reddy KR, Mantry PS, Cohen E, Bennett M, Sulkowski MS, et al. Efficacy of direct-acting antiviral combination for patients with hepatitis $\mathrm{C}$ virus genotype 1 infection and severe renal impairment or end-stage renal disease. Gastroenterology. 2016;150(7):1590-8.

44. Sherigar JM, Gayam V, Khan A, Mukhtar O, Arefiev Y, Khalid M, et al Clinical efficacy and tolerability of direct-acting antivirals in elderly patients with chronic hepatitis C. Eur J Gastroenterol Hepatol. 2017;29(7):767-6

45. Younossi ZM, Stepanova M, Nader F, Henry L. Patient-Reported Outcomes of Elderly Adults with Chronic Hepatitis C Treated with Interferon-and Ribavirin-Free Regimens. J Am Geriatr Soc. 2016;64(2):386-93.

46. Holmes JA, Yu M-L, Chung RT. Hepatitis B reactivation during or after direct acting antiviral therapy-implication for susceptible individuals. Expert Opin Drug Saf. 2017; Jun 3(16):651-72.

47. Pramoolsinsap C, Poovorawan Y, Hirsch P, Busagorn N, Attamasirikul K. Acute, hepatitis-A super-infection in HBV carriers, or chronic liver disease related to HBV or HCV. Ann Trop Med Parasitol. 1999;93(7):74551.

48. Centers for Disease Control. Recommended Immunization Schedules http://www.cdc.gov/vaccines/vdp-vac/vpd-list.htm. Retrieved March 16, 2017

49. Back DJ, Burger DM. Interaction between amiodarone and sofosbuvirbased treatment for hepatitis $\mathrm{C}$ virus infection: potential mechanisms and lessons to be learned. Gastroenterology. 2015;149(6):1315-7.

50. Yoshida EM, Sulkowski MS, Gane EJ, Herring RW, Ratziu V, Ding $\mathbf{X}$, et al. Concordance of sustained virological response 4,12 , and 24 weeks post-treatment with sofosbuvir-containing regimens for hepatitis $\mathrm{C}$ virus. Hepatology. 2015;61(1):41-5

51. Jacobson IM, Lim JK, Fried MW. American Gastroenterological Association Institute Clinical Practice Update-Expert Review: Care of Patients Who Have Achieved a Sustained Virologic Response After Antiviral Therapy for Chronic Hepatitis C Infection. Gastroenterology. 2017;152(6):1578-87.

52. Kattakuzhy SM. High Efficacy of HCV Treatment by Primary Care Providers: The ASCEND Study. Age. 2016;58(58.2):59. 